Review

\title{
Trophic Interactions Between Insects and Stream-Associated Amphibians in Steep, Cobble-Bottom Streams of the Pacific Coast of North America
}

\section{Trisha Atwood * and John S. Richardson}

Department of Forest Sciences, University of British Columbia, 3041-2424 Main Mall, Vancouver, BC V6T 1Z4, Canada; E-Mail: john.richardson@ubc.ca

* Author to whom correspondence should be addressed; E-Mail: tatwood16@gmail.com; Tel.: +1-604-838-8959; Fax: +1-604-822-9102.

Received: 16 February 2012; in revised form: 22 March 2012 / Accepted: 26 March 2012 /

Published: 10 April 2012

\begin{abstract}
Two native, stream-associated amphibians are found in coastal streams of the west coast of North America, the tailed frog and the coastal giant salamander, and each interacts with stream insects in contrasting ways. For tailed frogs, their tadpoles are the primary life stage found in steep streams and they consume biofilm from rock surfaces, which can have trophic and non-trophic effects on stream insects. By virtue of their size the tadpoles are relatively insensitive to stream insect larvae, and tadpoles are capable of depleting biofilm levels directly (exploitative competition), and may also "bulldoze" insect larvae from the surfaces of stones (interference competition). Coastal giant salamander larvae, and sometimes adults, are found in small streams where they prey primarily on stream insects, as well as other small prey. This predator-prey interaction with stream insects does not appear to result in differences in the stream invertebrate community between streams with and without salamander larvae. These two examples illustrate the potential for trophic and non-trophic interactions between stream-associated amphibians and stream insects, and also highlights the need for further research in these systems.
\end{abstract}

Keywords: aquatic insects; biofilms; coastal giant salamander; competition; predation; streams; tailed frog; trophic interactions 


\section{Introduction}

Stream foodwebs around the globe are typically dominated numerically and in terms of biomass by invertebrates, particularly the larval stages of aquatic insects. Aquatic insects fill many trophic positions in streams, feeding on algae and biofilms (grazers), plants (herbivores), detritus (detritivores of fine and coarse particles of organic matter), and other animals (predators) [1,2]. Vertebrates living in streams often prey upon stream insects, but also interact in other ways as competitors or through other non-trophic interactions, for instance through bioturbation (disturbing of sediments or the insects themselves). Stream fishes are well known for feeding on invertebrates [3], but larval and adult amphibians in streams can also have impacts on aquatic insect populations [4-6].

Interactions between amphibians and insects in ponds have demonstrated a variety of competition and predation interactions [7-9]. Competition between amphibians and insects has been shown to have strong influences on pond community structure, and occur within both the grazer [9] and predator guilds [10]. Predation interactions between amphibians and insects can go in both directions, with insects preying upon amphibian larvae [11,12], and amphibians, particularly salamanders, feeding on aquatic insects $[8,13,14]$. Predatory insects (e.g., dytiscids, anisopterans) can influence amphibian communities in ponds at the larval or embryonic stages $[15,16]$. Alternatively, the effect of aquatic amphibian predators in ponds can be substantial and can influence composition of both pelagic [14] and benthic taxa [8]. To date, most interactions described between amphibians and aquatic insects come from studies conducted in ponds.

The abundance and diversity of amphibians in stream ecosystems around the planet suggest that they are important ecological components for the assembly of stream insect communities [17-20], and there is evidence for this from a number of studies, as reviewed by Davic and Welsh [18]. Concern over global declines of amphibian species is exacerbated by the potential for widespread changes to ecosystems and ecosystem services resulting from such species declines [21]. We use two stream-dwelling amphibian species from the Pacific Northwest of North America to illustrate the possible interactions with aquatic insects, and their potential for population- and community-level consequences. These two species are the tailed frog, Ascaphus truei Stejneger (Anura: Leiopelmatidae), a species that grazes on rock biofilms as tadpoles, and Dicamptodon tenebrosus Baird and Girard (Caudata: Dicamptodontidae), the coastal giant salamander, which is predaceous as larvae and adults. We first introduce these species, and then review the evidence for their indirect and direct interactions (competition and predation) with aquatic insects. Finally we explore the potential for higher-order interactions between amphibians and insects in streams [4-6,22].

Natural History of A. truei and D. tenebrosus

The tadpoles of $A$. truei inhabit cold $\left(5-18{ }^{\circ} \mathrm{C}\right)$, perennial streams with steep gradients and coarse substrates within the Pacific Northwest of the United States and southwestern portions of British Columbia, Canada [23]. Coarse (e.g., cobble) substrates provide both relatively large crevices for refuge and flat surfaces for foraging. Ascaphus truei are "life-history omnivores", i.e., as adults they are carnivores feeding on stream and terrestrial insects, however, in their tadpole stage they are herbivores which graze on biofilms on rock surfaces [24]. 
The tadpoles of $A$. truei use their ventrally flattened bodies and a suctorial oral disk with a single toothblade to forage for biofilm on the smooth upper surfaces of cobbles in both riffles and pools within streams $[24,25]$. They forage primarily at night in an attempt to evade predators that hunt using visual cues, and seek refuge under rocks during the day. Although relatively large in size in comparison to their invertebrate grazer counterparts, A. truei tadpoles are quite small compared to other stream vertebrates reaching only $\sim 1 \mathrm{~g}$ wet mass before metamorphosis [24]. As a result of their small size, A. truei tadpoles fall prey to many aquatic and semi-aquatic predators, e.g., salamanders, frogs, fish, snakes, and shrews [26]. Predators of $A$. truei tadpoles may be an important control on their influence on stream ecosystems, as their predators can impact their grazing by both reducing tadpole abundance through consumption and altering tadpole foraging behavior through trait-mediated effects [26]. Although studies have shown that predators are capable of drastically reducing the abundance of A. truei tadpoles [26], they still can represent greater than $90 \%$ of the total herbivore biomass in streams they inhabit [25]. Thus, as a result of their superior size compared to many stream macroinvertebrates, A. truei tadpoles may be capable of creating competitive pressure among grazers and may have large influences on primary production within their ecosystems [4].

Larvae, and occasionally adults, of D. tenebrosus inhabit small, low elevation (below 1,200 m) streams along the west coast of North America from north-western California, USA to the south-western portion of British Columbia, Canada [27]. Aquatic stages of D. tenebrosus are typically associated with narrow, shaded streams with coarse substrate and an abundance of pools [28-30]. Unlike A. truei, D. tenebrosus do not undergo an ontogenetic shift in trophic position and are predaceous throughout their lives. Giant salamanders can represent over $90 \%$ of the predator biomass in small streams [28,31].

Aquatic D. tenebrosus are sit-and-wait predators, which use chemoreception to detect and locate their prey [32]. Dicamptodon tenebrosus feed almost exclusively on stream benthic organisms, although terrestrial insects which have fallen into the stream can make up a substantial portion of their diet [22]. In general, the diet of aquatic $D$. tenebrosus reflects local patterns in prey availability $[5,22]$. However, despite their generalist predator nature, larger, more active prey taxa appear to be the most frequently consumed by all size classes of aquatic D. tenebrosus [22]. Feeding occurs throughout the day and night, although their diel activity patterns suggest that they should be largely feeding at night when they are most active [22]. This type of behavior is hypothesized to occur in response to changes in prey activity and microhabitat use [33]. Due to their large size and generalist feeding behavior, aquatic $D$. tenebrosus act as top predators in many headwater streams.

\section{Trophic interactions}

\subsection{Amphibians as Competitors with Insects: Competition Between A. truei Tadpoles and Grazer Insects}

In order to demonstrate the occurrence of competition between two species, a study must first show an adverse effect of one species on the abundance, growth, or survival of another species, and second the study must provide a mechanistic understanding for its results. Studies that successfully incorporate both of these attributes are particularly limited for examining competition between amphibians and stream insects. There are, however, a few studies that provide insight into possible competitive interactions between these two groups, some of which will be described below [4,34-36]. 
Competition between stream insects and amphibians can occur either directly or indirectly. The most common and easily observable competitive interaction is exploitative competition, involving mutual resource depletion by two or more competitors [37]. Another form of competitive interaction between amphibians and stream insects that is often indirectly observed, but rarely directly tested, is interference competition. Interference competition is a direct interaction where one species injures or displaces another species while accessing a shared resource [38]. A third type of competitive interaction called apparent competition, where prey species indirectly depress one another by increasing the abundance of a shared predator [39,40], and might occur between stream insects and amphibians; however, to our knowledge no studies have examined this. Although there are several examples of competition between amphibians and stream insects across all functional feeding groups, we will focus on the competitive interactions between the tadpoles of $A$. truei and stream macroinvertebrates. The relationships between $A$. truei and stream macroinvertebrates are especially interesting because A. truei likely exerts both interference and exploitative interactions on stream insects [35].

\subsubsection{Exploitative Competition}

From current research, it is unclear whether $A$. truei tadpoles are effective competitors with grazer insects. However, several characteristics of $A$. truei tadpoles suggest that they have the ability to out compete many grazer insects. First, A. truei tadpoles are larger than the majority of stream insects, accounting for $90 \%$ of the herbivore biomass in streams they inhabit [25]. Second, A. truei tadpoles have much higher metabolisms, requiring them to acquire more food than grazer insects. Third, A. truei tadpoles are more mobile than grazer insects and can forage in a larger area. Studies examining exploitative competition between $A$. truei tadpoles and grazer insects, however, have mixed results as to the occurrence of exploitative competition. The first study to investigate exploitative competition between $A$. truei tadpoles and stream macroinvertebrates was conducted by Lamberti et al. [4]. This study found that the presence of $A$. truei tadpoles had substantial impacts on periphyton biomass and chlorophyll $a(\mathrm{Chl} a)$ concentrations, reducing them by as much as $98 \%$. In combination with reductions in abundance of periphyton, Lamberti et al. [4] found that in some cases A. truei tadpoles reduced the abundance of small grazer insects by more than 50\%. In contrast to Lamberti et al.'s [4] study, Rosenfeld [34] found slight reductions, which were not statistically different, in Chl $a$ concentrations and the abundance of grazing chironomids between streams with $A$. truei tadpoles compared to streams without them. Finally, a study by Kiffney and Richardson [25] found that $A$. truei tadpoles did not reduce periphyton biomass. In fact, mean periphyton biomass was slightly, although not significantly, higher than control treatments. With respect to A. truei's effect on grazing insects, the authors found that in the presence of tadpoles, grazing chironomid abundance decreased by $21 \%$ and mayfly abundance decreased by as much as $63 \%$.

The variation in the strength of $A$. truei tadpole interactions with grazer insects may be due to differences in environmental factors (both biotic and abiotic). Several studies have documented that interaction strengths are variable with time [41-43] and that even small changes in environmental factors (e.g., temperature) can influence the strength of species interactions [44]. Environmental changes can influence species interactions by affecting the performance of one or multiple species, thus influencing how that species interacts with other species. Several factors have been found to 
influence $A$. truei's interactions with both other grazers and their food resource. For example, one study found that $A$. truei had a greater effect on grazer mayfly abundance in nutrient enriched treatments than non-enriched treatments [35]. Another study found that periphyton in some British Columbian streams was controlled by $A$. truei grazing, while in other streams periphyton was controlled by light levels despite the presence of $A$. truei tadpoles [36]. The variation in the results presented above suggests that the outcomes of interactions between $A$. truei tadpoles and grazer insects are complex and perhaps context dependent. In most cases the studies presented above suggest a combination of exploitative and interference competition.

\subsubsection{Interference Competition}

Consumer traits have strong influences on community interactions $[38,45,46]$ and body size has been used to identify "key" or "dominant" species within a system [47]. In general, A. truei tadpoles are larger than most common macroinvertebrate grazers. Upon hatching, A. truei tadpoles are $\sim 11 \mathrm{~mm}$ in length and grow to a maximum of $\sim 65 \mathrm{~mm}$ close to the time of metamorphosis [48]. The final length of A. truei tadpoles is over twice that of the trichopteran Dicosmoecus gilvipes (Hagan), a large grazer insect common in streams of the Pacific Northwest, USA [49]. Ascaphus truei's larger size almost inevitably conveys an advantage for space over macroinvertebrate grazers. However, antagonistic encounters, and thus the potential for interference competition, have only been indirectly observed [35,50].

A study done by Kiffney and Richardson [35] found evidence that suggests interference competition may be occurring between $A$. truei and stream insect grazers. In this study, the authors examined the individual and joint effects of $A$. truei tadpoles and nutrient additions on periphyton biomass and insect grazer abundance in experimental stream channels. This study showed that the presence of $A$. truei tadpoles decreased insect grazer abundance. However, tadpoles were not able to significantly reduce periphyton biomass. Additionally, despite a substantial increase in the biomass of their shared periphyton resource, grazer insect abundance in the presence of tadpoles was in some cases lower than control treatments. Results from this study show complex interactions; however, they do suggest the possibility of antagonistic behavior by A.truei towards insect grazers.

\subsubsection{Difference in Resource Use}

The level of niche and functional overlap between $A$. truei tadpoles and stream insects is important for understanding how stream ecosystem function will be impacted should $A$. truei tadpole populations decline due to anthropogenic disturbances, such as forest harvest. However, the details of differences in resource use between $A$. truei tadpoles and stream insects are unknown. The mouthparts of $A$. truei and most insect grazers differ in terms of selectivity and how closely they can crop biofilms from stone surfaces [45]. With increased densities of A. truei tadpoles there was a decelerating rate of loss of algae [36], suggesting algae may have a spatial refuge from A. truei if they are very small or in crevices of rocks. By virtue of their smaller body size and smaller mandibles, grazer insects (e.g., Glossosoma and Stenonema) may be able to further reduce biofilm standing crop beyond what $A$. truei is capable of [45], but this hypothesis requires testing. There are additional questions regarding resource use and potential interactions between $A$. truei tadpoles and grazer insects that warrant further 
investigation. (1) To what extent do dietary components overlap between $A$. truei tadpoles and grazer insects? (2) What is the extent of spatial overlap between species? (3) What is the extent of temporal (diurnal and seasonal) overlap between species? (4) What is the total overlap among species with respect to space, time, and diet dimensions? (5) Which species of grazer insects are the most similar (or dissimilar) to A. truei tadpoles with respect to niche? (6) Which grazer insect species pose the greatest competitive threat to $A$. truei tadpoles?

\subsection{Predation}

Aquatic forms of D. tenebrosus are voracious and abundant predators in streams they inhabit [22]. Murphy and Hall [31] reported that larval D. tenebrosus represented $90 \%$ of the predator biomass in small Oregon and northern Californian streams. Larval D. tenebrosus are obligate benthic predators, feeding on stream and some drowned terrestrial macroinvertebrates and tadpoles [22]. Although larval D. tenebrosus are more active at night, Parker [22] found no difference in stomach content mass and the proportion of intact prey between night and day, suggesting that larval D. tenebrosus are opportunistic predators, feeding whenever prey presents itself. Due to their opportunistic feeding behavior and their large abundance, especially in fishless streams, aquatic D. tenebrosus may have strong influences on stream macroinvertebrate abundance and exert indirect effects on algal and detrital biomass and assemblages through tri-trophic cascades.

Although larval and neonate D. tenebrosus act as top aquatic predators in fishless streams, intraguild predation can occur in streams containing salmonids [5,51]. Adult and older Dicamptodon larvae can defend themselves from fish and other conspecific predators both behaviorally and with noxious skin secretions, however, young-of-year Dicamptodon larvae lack chemical defenses [51]. As a result, young-of-the-year Dicamptodon need adequate refuge from predators, which may also explain the correlation between the presence of larval $D$. tenebrosus and coarse benthic substrates. Although fish can effectively prey on Dicamptodon salamanders, they also act as competitors for food resources, as benthic macroinvertebrates make up a sizeable portion of stream salmonid [52] and larval D. tenebrosus diets [22]. Thus, predators of $D$. tenebrosus may influence the impacts of this species on stream communities both through consumption and exploitative competition.

There have been few considerations of the impacts of $D$. tenebrosus as top predators in stream communities. However, in one such experiment three pools in a stream were divided medially with mesh dividers to create three pairs of enclosures, with one of each pair having giant salamander larvae at natural densities, and the other member of each pair with all salamanders removed [53]. The presence of $D$. tenebrosus resulted in large reductions in the densities of large-bodied invertebrate species, of which many were predaceous aquatic insects. However, some smaller-bodied insects, such as Baetis spp. and orthocladiine chironomids, actually increased in the presence of the salamander larvae, suggesting an indirect effect of the salamanders by releasing these small species from predation pressure from the larger invertebrates [53].

To examine whether giant salamander larvae have a detectable effect on benthic communities in another set of small streams, we collected five benthic samples from each of 18 streams in the Chilliwack area of southwestern British Columbia [54]. We contrasted the stream insect communities of streams with and without (i.e., not detected) giant salamander larvae, with nine of each category of 
stream. Canonical discriminant analysis was used to test for differences associated with salamander presence in the relative abundances of benthic invertebrates (PROC CANDISC, SAS ver. 9.2, SAS Inc, Cary, NC). There was no significant difference $(p=0.44, \mathrm{n}=18)$ found between streams with or without salamanders. This suggests that while these salamanders are the top predator in many streams, they do not always lead to shifts in community structure, and that perhaps their effects are contextdependent.

\section{Population and Community-Level Consequences of Amphibian-Insect Trophic Interactions}

Stream insects and amphibians interact through trophic and non-trophic mechanisms. However, there has been very little consideration of the population dynamical effects of these interactions, despite evidence they may be considerable. Moreover, there may be community-scale consequences of these interactions.

Interactions between pond amphibians and insects have been the subject of many experiments. In pond mesocosms, the competitive effects of aquatic insects on growth of Hyla and Bufo tadpoles was of a similar or greater magnitude to that of the two amphibian species on each other [7]. The mechanism for that competitive effect was demonstrated to be depletion of the periphyton resource consumed by both of the amphibian tadpoles and the aquatic insects [7]. Study of tailed frog tadpoles at a range of densities has demonstrated the ability of that species to depress periphyton resources in streams [36], but as with other studies, the consequences for insect populations are rarely determined.

\section{Conclusions}

Above we have reviewed the limited evidence of how two particular species of stream amphibians might interact with aquatic insects. Many amphibians have complex life cycles in which different life stages may occupy different trophic levels. We have used these species as examples of the potential for interesting competitive and predator-prey interactions that might have large roles in stream foodwebs. Given the conservation concerns for amphibian populations globally, the reduction or local losses of stream amphibians may have profound effects for stream communities and ecosystem functions [18]. A greater appreciation for the roles of amphibians in stream communities would further support efforts being made to conserve species and their habitats.

An emphasis in the literature for stream insects has been on the effects of predaceous fish on the daily timing of foraging behavior of insects, and to some extent the population dynamical consequences of fish predation [7-9]. There have been few studies that have detailed the interactions and quantitative effects of amphibians on stream insects [4,5,35]. Given that amphibian biomass can be considerable in some streams, and in some cases fill the role of top predator, it is surprising that there has been so little consideration of the population-level interactions between stream insects and amphibians. There is great opportunity to explore the impacts of amphibians on stream insect populations given that the densities of these amphibians are easily manipulated experimentally. 


\section{References}

1. Cummins, K.W.; Klug, M.J. Feeding ecology of stream invertebrates. Annu. Rev. Ecol. Syst. 1979, 10, 147-172.

2. Wallace, J.B.; Webster, J.R. The role of macro-invertebrates in stream ecosystem function. Annu. Rev. Entomol. 1996, 41, 115-139.

3. Flecker, A.S. Fish predation and the evolution of invertebrate drift periodicity-Evidence from neotropical streams. Ecology 1992, 73, 438-448.

4. Lamberti, G.A.; Gregory, S.V.; Hawkins, C.P.; Wildman, R.C.; Ashkenas, L.R.; Denicola, D.M. Plant-herbivore interactions in streams near Mount St. Helens. Freshw. Biol. 1992, 27, 237-247.

5. Parker, M.S. Feeding ecology of stream-dwelling Pacific giant salamander larvae (Dicamptodon tenebrosus). Copeia 1994, 1994, 705-718.

6. Ranvestel, A.W.; Lips, K.R.; Pringle, C.M.; Whiles, M.R.; Bixby, R.J. Neotropical tadpoles influence stream benthos: Evidence for the ecological consequences of decline in amphibian populations. Freshw. Biol. 2004, 49, 274-285.

7. Morin, P.J.; Lawlor, S.P.; Johnson, E.A. Competition between aquatic insects and vertebrates: Interaction strength and higher order interactions. Ecology 1988, 69, 1401-1409.

8. Wissinger, S.A.; Whiteman, H.H.; Sparks, G.B.; Rouse, G.L.; Brown, W.S. Foraging tradeoffs along a predator-permanence gradient in subalpine wetlands. Ecology 1999, 80, 2102-2116.

9. Mokany, A.; Shine, R. Competition between tadpoles and mosquito larvae. Oecologia 2003, 135, 615-620.

10. Brodie, J.R., Jr.; Formanowicz, D.R., Jr. Prey size preference of predators: Differential vulnerability of larval anurans. Herpetologica 1983, 39, 67-75.

11. Cladwell, J.P.; Thorp, J.H.; Jervey, T.O. Predator-prey relationships among larval dragonflies, salamanders, and frogs. Oecologia 1980, 46, 285-289.

12. Buskirk, J.V. Interactive effects of dragonfly predation in experimental pond communities. Ecology 1988, 69, 857-867.

13. Holomuzki, J.R.; Collins, J.P.; Brunkow, P.E. Trophic control of fishless ponds by tiger salamander larvae. Oikos 1994, 71, 55-64.

14. Brodman, R.; Dorton, R. The effectiveness of pond-breeding salamanders as agents of larval mosquito control. J. Freshw. Ecol. 2006, 21, 467-474.

15. Anholt, B.R.; Werner, E.E. Predictable changes in predation mortality as a consequence of changes in food availability and predation risk. Evol. Ecol. 1998, 12, 729-738.

16. Rubbo, M.J.; Sheak, K.; Kiesecker, J.M. The influence of multi-stage predation on population growth and the distribution of the pond-breeding salamander, Ambystoma jeffersonianum. Can. J. Zool. 2006, 84, 449-458.

17. Duellman, W.E. Global Distribution of Amphibians: Pattern, Conservation, and Future Challenges; John Hopkins University Press: Baltimore, MD, USA, 1999.

18. Davic, R.D.; Welsh, H.H. On the ecological roles of salamanders. Annu. Rev. Ecol. Syst. 2004, 35, 405-434. 
19. Whiles, M.R.; Lips, K.R.; Pringle, C.M.; Kilham, S.S.; Brenes, R.; Connelly, S.; Colon-Gaud, J.C.; Hunte-Brown, M.; Huryn, A.D.; Montgomery, C.; Peterson, S. The consequences of amphibian population declines to the structure and function of neotropical stream ecosystems. Front. Ecol. Environ. 2006, 4, 27-34.

20. Colon-Gaud, C.; Whiles, M.R.; Kilham, S.S.; Lips, K.R.; Pringle, C.M.; Connelly, S.; Peterson, S.D.; Assessing ecological responses to catastrophic amphibian declines: Patterns of macroinvertebrate production and food web structure in Panamanian streams. Limnol. Oceanogr. 2009, 54, 331-343.

21. Stuart, S.N.; Chanson, J.S.; Cox, N.A.; Young, B.E.; Rodrigues, A.S.L.; Fischman, D.L.; Waller, R.W. Status and trends of amphibian declines and extinctions worldwide. Science 2004, 306, 1783-1786.

22. Parker, M.S. Size-selective predation on benthic macroinvertebrates by stream-dwelling salamander larvae. Arch. Hydrobiol. 1993, 128, 385-400.

23. Adams, M.J.; Bury, R.B. The endemic headwater stream amphibians of the American Northwest: Associations with environmental gradients in a large forested preserve. Glob. Ecol. Biogeogr. 2002, 11, 169-178.

24. Metter, D.E. Variation in the ribbed frog, Ascaphus truei Stejneger. Copeia 1967, 1967, 634-649.

25. Hawkins, C.P.; Gottschalk, L.J.; Brown, S.S. Densities and habitat of tailed frog tadpoles in small streams near Mt. St. Helens following the 1980 eruption. J. N. Am. Benthol. Soc. 1988, 7, 246-252.

26. Feminella, J.W.; Hawkins, C.P. Tailed frog tadpoles differentially alter their feeding behavior in response to non-visual cues from four predators. J. N. Am. Benthol. Soc. 1994, 13, 310-320.

27. Haycock, R.D. Pacific Giant Salamander Dicamptodon tenebrosus Status Report; Unpublished Report to the British Columbia Ministry of Environment, Wildlife Branch: Victoria, Canada, 1991.

28. Corn, P.S.; Bury, R.B. Logging in western Oregon: Responses of headwater habitats and stream amphibians. For. Ecol. Manag. 1989, 29, 39-57.

29. Richardson, J.S.; Neill, W.E. Headwater amphibians and forestry in British Columbia: Pacific giant salamander and tailed frogs. Northwest Sci. 2000, 72, 122-123.

30. Welsh, H.H.; Lind, A.J. Multiscale habitat relationships of stream amphibians in the Klamath-Siskiyou region of California and Oregon. J. Wildl. Manag. 2002, 66, 581-602.

31. Murphy, M.L.; Hall, J.D. Varied effects of clear-cut logging on predators and their habitat in small streams of the Cascade Mountains, Oregon. Can. J. Fish. Aquat. Sci. 1981, 38, 137-145.

32. Chases, L.G. The Behavioral Response of Larval Coastal Giant Salamanders, Dicamptodon tenebrosus, to Chemical Stimuli. M.A. Thesis, Humboldt State University, Arcata, CA, USA, 2008.

33. Petranka, J.W.; Petranka, J.G. Selected aspects of the larval ecology of the marbled salamander, Ambystoma opacum, in the southern portion of its range. Am. Midl. Nat. 1980, 104, 352-363.

34. Rosenfeld, J.S. The effect of large macroinvertebrate herbivores on sessile epibenthos in a mountain stream. Hydrobiologia 1996, 344, 75-79.

35. Kiffney, P.M.; Richardson, J.S. Interactions among nutrients, periphyton, and invertebrate and vertebrate (Ascaphus truei) grazers in experimental channels. Copeia 2001, 2001, 422-429. 
36. Mallory, M.A.; Richardson, J.S. Complex interactions of light, nutrients and consumer density in a stream periphyton-grazer (tailed frog tadpoles) system. J. Anim. Ecol. 2005, 74, 1020-1028.

37. MacArthur, R.H.; Levins, R. Competition, habitat selection, and character displacement in a patchy environment. Proc. Natl Acad. Sci. USA 1964, 51, 1207-1210.

38. Schoener, T.W. Field experiments on interspecies competition. Am. Nat. 1983, 122, 240-285.

39. Holt, R.D. Predation, apparent competition, and the structure of prey communities. Theor. Popul. Biol. 1977, 12, 237-266.

40. Holomuzki, J.R.; Feminella, J.W.; Power, M.E. Biotic interactions in freshwater benthic habitats. J. N. Am. Benthol. Soc. 2010, 29, 220-244.

41. Berlow, E.L.; Navarrete, S.A.; Briggs, C.J.; Power, M.E.; Menge, B.A. Quantifying variation in the strengths of species interactions. Ecology 1999, 80, 2206-2224.

42. Ruesink, J.L. Variation in per capita interaction strength: Thresholds due to nonlinear dynamics and nonequilibrium conditions. Proc. Natl Acad. Sci. USA 1998, 95, 6843-6847.

43. Kordas, R.L.; Dudgeon, S. Dynamics of species interaction strength in space, time and with developmental stage. Proc. R. Soc. B. 2011, 278, 1804-1813.

44. Sanford, E. Regulation of keystone predation by small changes in ocean temperature. Science 1999, 283, 2095-2097.

45. Lamberti, G.A.; Gregory, S.V.; Ashkenas, L.R.; Li, J.L.; Steinman, A.D. Influence of grazer type and abundance on plant-herbivore interactions in streams. Hydrobiologia 1995, 306, 179-188.

46. Otto, S.B.; Berlow, E.L.; Rank, N.E.; Smiley, J.; Brose, U. Predator diversity and identity drive interaction strength and trophic cascades in a food web. Ecology 2008, 89, 134-144.

47. Shurin, J.B.; Seabloom, E.W. The strength of trophic cascades across ecosystems: Predictions from allometry and energetics. J. Anim. Ecol. 2005, 74, 1029-1038.

48. Brown, H.A. Temperature and development of the tailed frog, Ascaphus truei. Comp. Biochem. Physiol. 1975, 50A, 397-405.

49. Wiggins, G.B.; Richardson, J.S. Biosystematics of Eocosmoecus, a new Nearctic caddisfly genus (Trichoptera: Limnephilidae; Dicosmoecinae). J. N. Am. Benthol. Soc. 1989, 8, 355-369.

50. Kupferberg, S. Facilitation of periphyton production by tadpole grazing: Functional differences between species. Freshw. Biol. 1997, 37, 427-439.

51. Rundio, D.E.; Olson, D.H. Antipredator defenses of larval Pacific giant salamanders (Dicamptodon tenebrosus) against cutthroat trout (Oncorhynchus clarki). Copeia 2003, 2003, 392-397.

52. Rundio, D.E.; Wipfli, M.S. Terrestrial invertebrates as salmonid prey and nitrogen sources in streams: Contrasting old-growth and young-growth riparian forests in southeastern Alaska, USA. Can. J. Fish. Aquat. Sci. 1997, 54, 1259-1269.

53. Parker, M.S. Feeding Ecology of Larvae of the Pacific Giant Salamander (Dicamptodon Tenebrosus) and Their Role as Top Predator in a Headwater Stream Benthic Community. Ph.D. Thesis, University of California, Davis, CA, USA, 1992.

54. Richardson, J.S. University of British Columbia, Vancouver, Canada, Unpublished work, 2012.

(C) 2012 by the authors; licensee MDPI, Basel, Switzerland. This article is an open access article distributed under the terms and conditions of the Creative Commons Attribution license (http://creativecommons.org/licenses/by/3.0/). 